\title{
CRÍTICA AO EXERCÍCIO ILIMITADO DO PODER SOBERANO PELAS NAÇÕES COMO FORMA DE VIOLAÇ̃̃O SISTEMÁTICA DOS DIREITOS HUMANOS NO ÂMBITO INTERNACIONAL
}

\author{
CRITICISM TO THE UNLIMITED EXERCISE OF SOVEREIGN POWER BY \\ NATIONS AS A FORM OF SYSTEMATIC VIOLATION OF HUMAN RIGHTS
}

\author{
${ }^{1}$ Gabriela Ferreira Pinto de Holanda Celestino \\ ${ }^{2}$ Kaliany Varjão de Santana Oliveira Guimarães
}

\section{RESUMO}

O presente artigo visa analisar o exercício ilimitado do poder soberano pelas nações e, consequentemente, do seu poder constituído como um meio de violação dos Direitos Humanos. Para isso, buscou-se utilizar exemplos de fatos ocorridos na contemporaneidade, bem como, embasamento em livros e artigos de importantes nomes do direito, da filosofia e da sociologia. Com os estudos empreendidos foi possível visualizar que quando o soberano age de acordo com os seus próprios interesses, impostos mediante o exercício da soberania e resguardados pelo poder constituído, dificulta-se a aplicabilidade dos Direitos Humanos na esfera mundial.

Palavras-chave: Soberania; Poder constituído; Direitos Humanos.

\begin{abstract}
This article aims to analyze and study the possibility of the exercise of sovereign, and consequently the exercise of its constituted power as a means for violation of human rights internationally. For this, we tried to use examples of events that took place in the contemporary world, as well as grounding in books and articles. With more research was possible to see that when the sovereign act according to their own interests, which are guided by the exercise of sovereign power and guarded by the constituted power, hinders the applicability of human rights on the world stage.
\end{abstract}

Key Words: Sovereignty; Constituted power; Human rights.

\footnotetext{
${ }^{1}$ Mestranda em Direito pela Universidade Federal de Sergipe - UFS, Sergipe (Brasil). Professora da Faculdade Maurício de Nassau - UNINASSAU, Maceió (Brasil). E-mail: gabriela_holanda@ hotmail.com

${ }^{2}$ Especialista em Direito Processual Civil pela Faculdade de Administração e Negócios de Sergipe FANESE/ESMESE, Sergipe (Brasil). Analista de Controle Externo II (Especialidade Jurídica) do Tribunal de Contas do Estado de Sergipe - TCE, Sergipe (Brasil).
} 


\section{INTRODUÇÃO}

$\mathrm{O}$ artigo tem por objetivo desenvolver uma crítica ao exercício indiscriminado do poder soberano pelas nações, o que ao longo da história justificou a prática dos mais diversos asos de violação de direitos humanos, notadamente, em Estados (tidos e havidos) de forte tradição democrática. O tema fora escolhido e desenvolvido com o intuito de abordar a necessidade de se promover a efetiva aplicabilidade dos direitos que tutelam a condição humana, independentemente de um status específico, seja ele vinculado à noção de nacionalidade ou de cidadania.

Ao analisar os fatos ocorridos ao longo da história da humanidade, constata-se que muitas nações, pautadas num suposto interesse de preservação do seu poder soberano, por vezes colocam em segundo plano a proteção da humanidade, na medida em que passam a encarar o ser humano, não como sujeito de direitos, mas como objeto e, portanto, supérfluo, desnecessário e indesejado quando não atendam aos seus interesses (por vezes, egoísticos).

Isso pode ser observado de forma evidente nos regimes totalitários, nos quais as pessoas que não interessavam ao detentor do poder soberano eram encarceradas (ou encerradas) em campos de concentração. "É, com efeito, uma nova forma de governo que, ao almejar a dominação total através do uso da ideologia e do emprego do terror para promover a ubiqüidade (sic) do medo, fez do campo de concentração o seu paradigma organizacional”. (LAFER, 1997)

Entretanto, tratar o ser humano como um objeto sem utilidade não foi uma exclusividade dos regimes totalitários. Infelizmente, essa cultura tem se alastrado pela contemporaneidade e, hoje, existem inúmeros episódios em que é possível visualizar o desrespeito à condição humana, mesmo em países democráticos, sempre sob a justificativa da necessidade de manutenção da ordem e/ou da segurança interna. Dois grandes exemplos que impactaram o ano de 2015, com repercussão nos mais diversos noticiários mundiais, foram a guerra na Síria (país não fundamentado sob um regime democrático, mas cujos nacionais buscaram refúgio em países europeus, alguns deles berços da noção moderna de Democracia) e o atentado terrorista em Paris.

Diante desse cenário global, necessária se faz a realização de um exame sobre esse entrave na concreta aplicabilidade dos Direitos Humanos na esfera mundial, o que passa pela imperiosa observação de que, justificados pelo exercício do poder soberano, muitos Estados admitem tudo ser possível, inclusive as investidas odiosas e violentas operadas contra a vida das pessoas; violência, esta, mantida e conservada pelo poder constituído de cada país (AGAMBEN, 2007). 
Vale destacar que o desenvolvimento do estudo se iniciou com a realização de pesquisa digital, com o fim de identificar casos práticos para serem apresentados ao longo do artigo, bem como, em livros e artigos de doutrinadores que são referências no tema em tela.

O desenvolvimento do presente artigo foi dividido em três tópicos, no primeiro, foi introduzido o tema através da apresentação de fatos históricos que traduzem o exercício da soberania e do poder constituído como forma de afastamento da aplicabilidade de Direitos Humanos internacionais; no segundo, é analisada a prática do poder soberano, em que, não excepcionalmente, cria verdadeiros estados de exceção, quando deveria ter por norte atuar em favor das pessoas, preservando e resguardando sua condição humana; no terceiro e último tópico, trata-se do papel do poder constituído na manutenção da soberania e, consequentemente, funcionando como um bloqueio para a aplicabilidade dos Direitos Humanos na escala global.

\section{FATOS HISTÓRICOS QUE TRADUZEM O EXERCÍCIO DA SOBERANIA E DO PODER CONSTITUÍDO COMO FORMA DE AFASTAMENTO DA APLICABILIDADE DE DIREITO HUMANOS INTERNACIONAIS}

A intolerância religiosa, o desprezo pelo ser humano e a busca desenfreada pelo poder de dominação vêm provocando inúmeros episódios de terror pelo mundo. Surgem guerras e atentados, nos quais o ser humano é visto como mero objeto diante de supostos interesses pautados na soberania de uma nação.

Muitas vezes as vítimas dessas guerras e atentados tornam-se refugiados e são encarados como verdadeiros estorvos para os demais países, e terminam condenados a viverem em campos de refugiados ou a morrerem na busca de um lugar que os aceite, nos quais possam viver de forma digna.

Deve-se destacar que o desrespeito à condição humana não é algo que surgiu na contemporaneidade, pululando na história os mais diversificados exemplos, entre eles, um ocorrido em pleno século XX, com forte repercussão até os dias atuais, que fora o surgimento do regime totalitário na Europa. Regime, esse, em que tudo se tornou possível e a dominação total era a tônica, onde se criaram campos de concentração, que lançaram terror sobre as pessoas, enxergadas como supérfluas e descartáveis (ARENDT, 2005).

Entretanto, urge ressaltar que a política de desvalorização humana implementada nos regimes totalitários continua a existir, como bem destaca Lafer (1997): 
No mundo contemporâneo continuam a persistir situações sociais, políticas e econômicas que, mesmo depois do término dos regimes totalitários, contribuem para tornar os homens supérfluos e sem lugar num mundo comum. Entre outras tendências, menciono a ubiqüidade (sic) da pobreza e da miséria; a ameaça do holocausto nuclear; a irrupção da violência, os surtos terroristas, a limpeza étnica, os fundamentalismos excludentes e intolerantes.

A continuidade de situações sociais, políticas e econômicas que tornam as pessoas supérfluas e sem lugar no mundo é possível de ser visualizada através de vários episódios atuais, a exemplo da guerra na Síria e do atentado terrorista em Paris, sendo o último utilizado como base de análise sobre os limites da soberania (ou a ausência deles) de uma nação e o respectivo exercício do seu poder constituído como formas de criação de um "estado de exceção" e de verdadeiras barreiras para o desenvolvimento e aplicabilidade dos Direitos Humanos no âmbito internacional.

Nesse cenário, é de bom alvitre dar-se início à análise do atentado terrorista que ocorreu em Paris:

(...) A manhã acordou inerte. As discussões televisivas que ocorreram imediatamente após os eventos parecem deixar claro que o 'estado de emergência', ainda que temporário, na verdade cria precedente para uma intensificação do estado de segurança. As questões debatidas na televisão incluem a militarização da polícia (de que modo "completar" esse processo), o espaço da liberdade, e a luta contra o "islã", este último entendido como uma entidade amorfa. Hollande, ao nomear isso como 'guerra', tentou parecer másculo, mas o que chamou atenção foi o aspecto imitativo de sua performance - tornou-se difícil, então, levar seu discurso a sério. E, no entanto, é esse agora o bufão que assume o papel de cabeça do exército (...) (FERREIRA, 2015).

Assim começa o relato da filósofa estadunidense Judith Butler, publicado no site da Revista Cult, acerca dos fatos mais recentes ocorridos a partir de 13 de novembro de 2015 na França, em que diversos pontos da cidade de Paris foram alvos de ataques atribuídos ao denominado Daesh ou ISIS (Estado Islâmico). Em sete pontos diferentes, quase que simultaneamente, alguns "terroristas", com modus operandi distintos, deixaram um saldo de 129 (cento e vinte e nove) mortos e 352 (trezentos e cinquenta e dois) feridos. Imediatamente, o presidente francês, François Hollande, veio a público para decretar o Estado de Emergência, determinando a proibição de quaisquer reuniões públicas, o fechamento de determinados espaços públicos, o sério controle da aduana, bem como, a possibilidade de revista de domicílios, dia ou noite, e detenções sem prévia autorização judicial. Dois dias depois, determina-se a prorrogação do Estado de Emergência por três meses e a modificação da Constituição, sem consulta prévia à população. O objetivo? 
(...) o aumento do efetivo policial e a possibilidade da mudança das modalidades da utilização de legítima defesa por parte da polícia, além de mudanças nos critérios do controle de identidade.

O mais surpreendente é ter acenado com a possibilidade da destituição da nacionalidade no caso de binacionais envolvidos em ações terroristas, proposta que é uma das bandeiras defendidas pela extrema-direita, não tendo eficácia comprovada, mas um caráter puramente simbólico.

$\mathrm{O}$ presidente qualificou como fundamental a possibilidade de poder destituir a nacionalidade de binacionais - mesmo os nascidos em solo francês - em casos que estejam envolvidos em casos de prática terrorista ou que representem uma ameaça aos interesses fundamentais da Nação. A isto completou sugerindo a expulsão de maneira acelerada, com procedimentos simplificados, de todos estrangeiros implicados em ações terroristas, além do chamado visto de regresso. Este, o «visto de regresso», de acordo com o presidente impediria o retorno de franceses envolvidos neste tipo de crime ao solo francês.

Em relação ao «visto de regresso», é necessário explicar que se tal medida for adotada fere a Convenção Europeia dos direitos humanos, pois desrespeita o direito de um nacional de retornar ao seu solo de origem.

Se aprovada a reforma na constituição, significará a cristalização de um estado de exceção nas leis da França. E tudo isto para responder a um sentimento de insegurança e medo, que os atentados suscitaram na população. (SANFE, 2015)

Além disso, a mudança constitucional anunciada previu mais autoridade policial para perseguir e controlar os tidos por suspeitos de terrorismo, endurecer as penas de crimes dessa natureza e transferir mais poder ao chefe do poder executivo. Ademais, tentando adaptar-se às mudanças, almejar a declaração de guerra em face de um não Estado (caso do ISIS). Houve ainda a propositura de medidas para fechamento de mesquitas e a definição de uma zona específica de residência dos considerados suspeitos.

O ex-presidente Nicolas Sarkozy disse que teriam de ser fixadas zonas determinadas
de residência para esses suspeitos (o estado de emergência permite) e colocar-lhes
braceletes eletrônicos de geolocalização. Laurent Wayquiez, secretário-geral do
partido de Sarkozy, Os Republicanos, propôs até mesmo a prisão desses suspeitos em
acampamentos especiais de internação. O Executivo, na realidade, não descarta a
possibilidade de obrigá-los a portar algum dispositivo para que possam ser localizados
a todo o momento.
Os líderes políticos também se referiram nestes dias à conveniência de tomar medidas
em relação aos discursos radicais nas mesquitas francesas. A líder da ultradireitista
Frente Nacional, Marine Le Pen, é partidária de fechar aquelas onde sejam feitos
sermões violentos. O ministro do Interior, Bernard Cazeneuve, disse no domingo que
é preciso fechar as que "preguem o ódio". Nesta segunda-feira, Valls afirmou que "é
preciso expulsar os que proferem discursos insuportáveis contra a República"
(CAÑAS, 2015).

Note-se que o quadro apresentado a partir dos ataques de novembro decretou não apenas o luto na cidade Luz, mas desencadeou uma série de decisões jurídico-políticas relevantes que arremessaram holofotes a algumas indagações pertinentes: estaria o filósofo italiano Giorgio Agamben correto ao propugnar que o estado de exceção se estabelece hodiernamente como regra? Por que ecoam nos discursos políticos em um dos países berço da democracia ocidental, 
com tanta naturalidade, termos ou expressões como "campos de detenção", "expulsão das bactérias" (termo utilizado para se referir aos imigrantes), "prisão de suspeitos sem prévia ordem judicial" e "restrição da liberdade para proteção da liberdade"? Afinal, poderíamos afirmar que a França se encaminha hoje para um período de indistinção entre democracia e totalitarismo?

Despiciendas maiores considerações históricas acerca da formação do Daesh ou ISIS e mesmo de juízos de valor acerca de suas práticas, importa examinar aqui como democracias ocidentais consolidadas, a exemplo da França (integrante da ONU, da União Europeia e signatária de diversos convenções de direitos humanos), sob o fundamento do medo e da necessidade de segurança, conseguem sem maiores formalidades instaurar um estado de exceção e decidir sobre a suspensão de todo um arcabouço de direitos em relação àqueles tidos ou escolhidos por inimigos do Estado, retirando-os, assim, da ordem jurídica e atuando contra eles segundo seus interesses.

\section{O EXERCÍCIO DA SOBERANIA E O RESPEITO À CONDIÇÃO HUMANA}

Giorgio Agamben $^{3}$, um dos filósofos mais influentes da contemporaneidade, desenvolveu em sua obra Homo Sacer, o poder soberano e a vida nua, a partir do conceito de biopolítica elaborada por Foucault, uma pesquisa que examina e critica o conceito tradicional de soberania. Seu objetivo, segundo expõe, é realizar um ponto de intersecção entre o modelo jurídico-institucional e o modelo biopolítico de poder, dado que, para ele, "a implicação da vida nua na esfera política constitui o núcleo originário - ainda que encoberto - do poder soberano" (AGAMBEN, 2007, p. 14).

Segundo o referido autor, "colocando a vida biológica no centro de seus cálculos, o Estado moderno não faz mais, portanto, do que reconduzir à luz o vínculo secreto que une poder à vida nua" (ibidem, p. 14). Agamben, portanto, não deixa margem para quaisquer dúvidas

\footnotetext{
${ }^{3}$ Giorgio Agamben nasceu em Roma, em 1942. Advogado, filósofo e autor de diversas obras, por meio das quais estabelece um diálogo permanente com inúmeros campos do saber, entre eles: filosofia, direito, teologia, linguística, antropologia, ciência política, literatura, gramática histórica, iconografia, sociologia, entre tantos outros. Lança seu primeiro livro em 1970, na Itália, intitulado O homem sem conteúdo. Entretanto, seus trabalhos mais conhecidos incluem sua investigação acerca dos conceitos de estado de exceção e homo sacer, notadamente nas obras: Homo Sacer, o poder soberano e a vida nua I (1995), Estado de exceção (2003), O reino e a glória (2007), O sacramento da linguagem: arqueologia do juramento (2008), Altíssima pobreza (2011) e Opus Dei: arqueologia do ofício (2012).
} 
quanto ao protagonismo de sua obra residir naquilo que ele denominou de vida nua, "isto é, a vida matável e insacrificável do homo sacer" (ibidem, p. 16).

\begin{abstract}
Uma obscura figura do direito romano arcaico, na qual a vida humana é incluída no ordenamento unicamente sob a forma de sua exclusão (ou seja, de sua absoluta matabilidade), ofereceu assim a chave graças a qual não apenas os textos sacros da soberania, porém, mais em geral, os próprios códices do poder político podem desvelar os seus arcanos (...) A tese foucaultiana deverá, então, ser corrigida ou, pelo menos, integrada no sentido de que aquilo que caracteriza a política moderna não é tanto a inclusão da zoé na pólis, em si antiguíssima, nem simplesmente o fato de que a vida como tal venha a ser objeto eminente dos cálculos e das previsões do poder estatal; decisivo é, sobretudo, o fato de que, lado a lado com o processo pelo qual a exceção se torna em todos os lugares a regra, o espaço da vida nua, situado originariamente à margem do ordenamento, vem progressivamente coincidir com o espaço político, e exclusão e inclusão, externo e interno, bíos e zoé, direito e fato entram em uma zona de irredutível indistinção" (ibidem, p. 16).
\end{abstract}

De uma forma bastante lacônica, poder-se-ia afirmar que Agamben compreende que a vida nua resta presa à política sob a forma de exceção e a decisão sobre a exceção é o modo por meio do qual se manifesta o poder soberano. Logo no início da Parte 1 da referida obra, intitulada Lógica da Soberania, Agamben expõe, fundamentado em Schmitt, o paradoxo da soberania, para quem:

“o soberano está, ao mesmo tempo, dentro e fora do ordenamento jurídico". Se o soberano é, de fato, aquele no qual o ordenamento jurídico reconhece o poder de proclamar o estado de exceção e de suspender, deste modo, a validade do ordenamento, então "ele permanece fora do ordenamento jurídico e, todavia, pertence a este, porque cabe a ele decidir se a constituição in toto possa ser suspensa" (Schmitt, 1922, p. 34). A especificação "ao mesmo tempo" não é trivial: o soberano, tendo o poder legal de suspender a validade da lei, coloca-se legalmente fora da lei. (SCHMITT apud AGAMBEN, 2007, p. 23

Assim sendo, o soberano é aquele que decide sobre a exceção: sobre quem será excluído da regra para, na exceção, ser incluído. Ou, reportando-se ao caso acima narrado: quem será excluído do ordenamento jurídico, para, a um só tempo, ser incluído no regime de emergência, em que tudo é possível. Eis, portanto, em termos muito simples o que o filósofo italiano anunciou: o monopólio da soberania estatal reside no poder de decisão, notadamente, na decisão sobre a exceção. Citando Schmitt, complementa:

A exceção é aquilo que não se pode reportar; ela subtrai-se à hipótese geral, mas ao mesmo tempo torna evidente com absoluta pureza um elemento formal especificamente jurídico: a decisão(...) O soberano cria e garante a situação como um todo na sua integridade. Ele tem o monopólio da decisão última. Nisto reside a essência da soberania estatal, que, portanto, não deve ser propriamente definida como monopólio da sanção ou do poder, mas como monopólio da decisão (...) O caso de exceção torna evidente do modo mais claro a essência da autoridade estatal. Aqui a 
decisão se distingue da norma jurídica e (para formular um paradoxo) autoridade demonstra que não necessita do direito para criar o direito. A exceção é mais interessante do que o caso normal (SCHMITT apud AGAMBEN, 2007, p. 24).

A exceção a qual Agamben se refere é aquela que define a estrutura da soberania e que detém contornos complexos, tendo em vista que, para ele, o que caracteriza propriamente a exceção é “que aquilo que é excluído não está, por causa disto, absolutamente fora da relação com a norma; ao contrário, esta se mantém em relação com aquela na forma da suspensão. $A$ norma se aplica à exceção desaplicando-se, retirando-se desta” (AGAMBEN, 2007, p. 25).

Examinado o caso acima narrado ocorrido na França à luz do que fora exposto acerca da teoria de Agamben, o soberano é aquele que decide sobre quem se encaixa no conceito de "suspeito" e, por meio da exceção, promove sua exclusão da regra, abandonando-o. Abandonado, o "suspeito" (que aqui pode bem se encaixar no conceito de homo sacer) não goza dos mais comezinhos direitos, por isso, ao ser "suspeito" pode ser preso sem prévia ordem judicial, pode ter seu domicílio invadido à noite sem determinação judicial prévia, pode ser monitorado eletronicamente dia e noite, pode ser incluído dentro de um campo especial de detenção para "suspeitos", pode passar por técnicas “especiais" de interrogatório, pode vir a ser expulso de seu país de origem mediante um procedimento célere e simplificado e pode vir a perder sua nacionalidade. Qualquer semelhança com o tratamento que fora dado àquele que se encaixasse no conceito de "judeu" da Alemanha nazista da Segunda Guerra Mundial não é mera coincidência.

As democracias modernas não se cansam de fornecer casos e situações em que a figura do homo sacer renasce e confirma a crítica ao poder soberano feita pelo filósofo italiano. Em um caso igualmente recente, poder-se-ia bem lembrar do USA Patriot Act, citado por Agamben em outra obra sua, intitulada Estado de Exceção (por meio da qual dá continuidade à tese acerca da figura do Homo Sacer), sobre o que aduz:

Os talibãs capturados no Afeganistão, além de não gozarem do estatuto de POW [prisioneiro de guerra] de acordo com a Convenção de Genebra, tampouco gozam daquele de acusado segundo as leis norte-americanas. Nem prisioneiros nem acusados, mas apenas detainees, são objeto de uma pura dominação de fato, de uma detenção indeterminada não só no sentido temporal, mas também quanto à sua própria natureza, porque totalmente fora da lei e do controle judiciário (AGAMBEN, 2004. p.14)

Entretanto, resta espantoso perceber que, embora tenham se tornado cada vez mais comuns os exemplos de "estado de exceção", com a suspensão do ornamento jurídico quando assim decide o poder soberano sobre determinadas pessoas ou grupos delas, não há, em 
contrapartida, o desenvolvimento de qualquer teoria do estado de exceção, de modo que se fixem limites, condições, freios, nesses períodos de crise.

Tanto é assim que, embora muito discutida e criticada por aliados, não existem dúvidas da possibilidade de modificação da Constituição Francesa, nos próximos dias, por proposta do presidente francês François Hollande, para a perda da nacionalidade por aqueles que sejam considerados "terroristas", ainda que tal medida viole frontalmente a Convenção Europeia dos Direitos do Homem, que reconhece em seu art. $3^{\circ}$, ipsis litteris:

\author{
ARTIGO $3^{\circ}$ \\ Proibição da expulsão de nacionais \\ 1. Ninguém pode ser expulso, em virtude de disposição individual ou coletiva, do \\ território do Estado de que for cidadão. \\ 2. Ninguém pode ser privado do direito de entrar no território do Estado de que for \\ cidadão.
}

Para Agamben, o estado de exceção, ainda que não declarado expressamente, é a resposta imediata do poder estatal aos conflitos internos mais incômodos, no entanto, ao ser instaurado "é essa terra de ninguém, entre o direito público e o fato político e entre a ordem jurídica e a vida" (AGAMBEN, 2004, p. 12), que permite a "legalização" do que seria, numa situação normal, impossível. Por isso, segundo ele:

\footnotetext{
O totalitarismo moderno pode ser definido, nesse sentido, como a instauração, por meio do estado de exceção, de uma guerra civil legal que permite a eliminação física não só dos adversários políticos, mas também de categorias inteiras de cidadãos que, por qualquer razão, pareçam não integráveis ao sistema político. Desde então, a criação voluntária de um estado de emergência permanente (ainda que, eventualmente, não declarado no sentido técnico) tornou-se uma das práticas essenciais dos Estados contemporâneos, inclusive dos chamados democráticos (ibid., p. 13)
}

Nesse diapasão, constata-se que havendo uma alteração na Constituição da França para a retirada da nacionalidade francesa daqueles que sejam considerados "terroristas", além de articular uma afronta ao artigo $3^{\circ}$ da Convenção Europeia do Direitos do Homem, estar-se-ia criando uma muralha robusta que, ao final, impedirá a aplicabilidade e efetividade, de modo universal, dos Direitos Humanos.

Desse modo, estar-se-ia, mais uma vez, diante de situação semelhante àquela ocorrida nos regimes totalitários, dado que ao perder o direito à nacionalidade ou à cidadania, as pessoas não poderão se valer da quase totalidade dos direitos humanos historicamente reconhecidos, sem os quais, consequentemente, perderão sua noção de dignidade (e mesmo de inclusão e/ou 
de pertencimento à espécie humana), tornando-se, pois, invisíveis, desnecessárias e indesejáveis (LAFER, 1997).

Verifica-se, assim, que o status de nacional ou de cidadão está intimamente relacionado ao exercício e ao efetivo respeito de direitos historicamente conquistados, como bem destaca Celso Lafer ao mencionar o entendimento de Hannah Arendt:

A experiência histórica dos displaced people levou Hannah Arendt a concluir que a cidadania é o direito a ter direitos, pois a igualdade em dignidade e direito dos seres humanos não é um dado. É um construído da convivência coletiva, que requer o acesso a um espaço público comum. Em resumo, é esse acesso ao espaço público - o direito de pertencer a uma comunidade política - que permite a construção de um mundo comum através do processo de asserção dos direitos humanos. (LAFER, 1997)

Ao encarar o ser humano como mero objeto supérfluo, deixando de assegurá-los direitos mínimos para a preservação da sua condição humana, o mundo voltará a vivenciar tempos de barbárie, o que já passou a ser uma constante em nosso cotidiano, como bem retrata o trecho a seguir:

E aqui chegamos ao nosso milênio infestado pelos ecos dessa ideologia e ameaçado pelo retorno de um sistema político em que os idênticos condenam à morte os que consideram não merecer viver. Logo, há uma ligação íntima e muda entre a crueldade nazi e o retorno da barbárie no século 21. Aliás, nossa contemporaneidade começa sofrendo traumas massivos. Nova York e Madrid testemunham a onipresença do traumático na cultura de nosso tempo. E os mares do sudeste asiático coalhados de cadáveres testificam o genocídio de refugiados fugitivos dos campos de concentração atuais. O problema se agrava pelo fato de a política pós-moderna repetir o sonho nazista de fundamentar a categoria da cidadania na identidade do sujeito ao solo, à pátria, em detrimento do reconhecimento do Outro. Identidades nacionais se prestam fundamentalmente à rejeição de muitos. Daí ao estado de barbárie há só um passo: os fundamentalismos judaico, cristão e islâmico praticam em nome da identidade religiosa assassinatos em massa. Ecos dos Autos de Fé na Alemanha nazista, prenúncio do extermínio de milhões de homens, mulheres e crianças, soaram alto em fevereiro de 2015, quando o Estado Islâmico tocou fogo na biblioteca de Mossul, no Iraque. Em seguida assistimos ao real da cena de horror em que jihadistas queimam os não idênticos, pilotos capturados e enjaulados. Lá onde se queimam livros terminase queimando pessoas (Heine, 1797-1856). (FUKS, 2015)

E nesse contexto histórico e político, deparamo-nos com a necessidade de repensar os limites do exercício do poder soberano, especialmente quando ele se cruza com o Direito Internacional público, que com as suas convenções fixam direitos que visam proteger o ser humano. 


\section{A MANUTENÇÃo da SObERANia PELo PODER CONSTituído E SUA IMPLICAÇÃO NA UNIVERSALIZAÇÃO DOS DIREITOS HUMANOS}

Arendt identifica a capacidade que os homens possuem de se comunicarem e de se cooperarem como a fonte causadora do poder. E essa potencialidade se traduz por meio da ação e comunicação conjunta e compartilhada (ARENDT, 2000).

[...] o poder só é efetivado enquanto a palavra e o ato não se divorciam, quando as palavras não são vazias e os atos não são brutais, quando as palavras não são empregadas para velar intenções, mas para revelar realidades, e os atos não são usados para violar e destruir, mas para criar relações e novas realidades. [...] O poder é sempre um potencial de poder, não uma entidade imutável, mensurável, [...] o poder passa a existir entre os homens quando eles agem juntos e desaparece no instante em que eles se dispersam (ARENDT, 2000, p.212).

E o comando do soberano só é realizado quando autorizado por esse poder que emana do povo. Quando a ação conjunta dos homens não for a resultante desse poder, ele deixará de ser poder-potência, para ser poder-violência.

Nesse contexto, Giorgio Agamben (2004) afirma que o paradoxo da soberania se mostra evidente no problema do poder constituinte e sua relação com o poder constituído.

\footnotetext{
Como o poder soberano se pressupõe como estado de natureza, que é assim mantido em ralação de bando com o estado de direito, assim ele se divide em poder constituinte e poder constituído e se conserva em relacionamento com ambos, situando-se em seu ponto de indiferença (AGAMBEN, 2004, p. 48).
}

Cumpre fazer uma breve distinção do ponto de vista de alguns doutrinadores acerca do poder constituído e poder constituinte, para que depois possamos demonstrar a relação deles com o poder soberano.

Para Burdeau (apud AGAMBEN, 2004, p. 47): “Os poderes constituídos existem somente no Estado: inseparáveis de uma ordem constitucional preestabelecida, eles necessitam de uma moldura estatal da qual manifestam a realidade", já o poder constituinte "situa-se fora do Estado; não lhe deve nada, existe sem ele, é a fonte cujo uso que se faz de sua corrente não pode jamais exaurir".

Noutra banda, para Benjamin (apud AGAMBEN, 2004), poder constituinte é a violência que põe o direito, e poder constituído é a violência que conserva o direito. 
Destaca-se, ainda, sob a ótica de renomados doutrinadores, a importante relação que existe ente poder constituinte e soberania.

Hannah Arendt (apud AGAMBEN, 2004) fala da importância da instituição de um poder constituinte para que possa conferir soberania à nação, e, ao menos, alguma duração e estabilidade à república, como fruto de um processo revolucionário.

O poder constituinte "se apresenta como expressão de um pode soberano ou não se deixa, em todo caso, isolar facilmente dele" (AGAMBEN, 2004, p.50).

Para Schmitt (apud AGAMBEN, 2004, p. 50) o poder constituinte é teoricamente distinto do poder soberano, pois trata-se de "vontade política" que está "antes e acima de qualquer procedimento legislativo constitucional”.

Já Sieyès (apud AGAMBEN, 2004) entende o poder constituinte como vontade constituinte do povo ou da nação, não sendo possível distinguí-lo da soberania popular ou nacional. Para o referido doutrinador há um confusão entre sujeito constituinte e sujeito soberano.

Posicionamento diferente é o adotado por Negri (apud AGAMBEN, 2004), o qual compreende a soberania como fim do poder constituinte, como esgotamento da liberdade que o poder constituinte é portador.

Demonstrado o que se compreende por poder constituído e poder constituinte, bem como a relação desse último poder com a soberania, deve-se abordar o papel do poder constituído frente ao poder soberano.

O poder constituinte pode ser independente da existência do Estado e o responsável pela criação do direito, mas será o poder constituído o incumbido de conservar esse direito e de manter a ordem estatal, por meio da preservação da soberania nacional.

Retomando o caso que fora utilizado como exemplo para o desenvolvimento do presente trabalho (o atentado terrorista que o correu em Paris, em novembro de 2015), foi explanada no tópico anterior a eminente possibilidade de uma alteração na Constituição Francesa, para a perda da nacionalidade por aqueles que sejam considerados "terroristas", de modo que, levada a cabo, não existirão dúvidas de que afrontará diretamente o artigo $3^{\circ}$ da Convenção Europeia dos Direitos do Homem.

Essa mudança constitucional é operada pelo poder constituinte, mas a manutenção dessa nova ordem restará, ao final, como atribuição do poder constituído, a quem, consequentemente, será delegado o dever de promover e tutelar esse poder soberano. 
Assim, ao preservar a força de um poder soberano, que numa visão egoísta, busca unicamente a preservação de interesses internos da França (ou a preservação dos direitos de uma dada categoria de nacionais e cidadãos franceses que bem se encaixem no conceito de "não terroristas" ou "não suspeitos"), em detrimento de Direitos Humanos previstos em uma convenção da qual o país é signatário, o poder constituído dará sinais claros de seu não compromisso com a efetivação desses direitos que tutelam a condição humana no âmbito internacional.

Desse modo, para que haja uma efetiva aplicabilidade das convenções que tratam sobre Direitos Humanos na esfera mundial, indispensável que se faça uma crítica realista ao exercício da soberania e, consequentemente, do poder constituído, de modo que a decisão operada pelo soberano encontre freios e limites efetivos nas referidas convenções e nos demais direitos conquistados pelos homens ao longo da história da humanidade. Uma resposta provável a esse dilema, talvez, possa ser encontrada no pensamento de Hannah Arendt que propugna uma relativização do poder soberano ou uma transcendência do conceito de soberania nacional como expediente à garantia dos direitos do homem e de efetivo respeito à vida digna, independentemente do status que carregue, seja ele vinculado à noção de nacionalidade ou de cidadania.

\begin{abstract}
A construção de um mundo comum, baseado no direito de todo ser humano à hospitalidade universal (Kant) e contestado na prática pelos refugiados, pelos apátridas, pelos deslocados, pelos campos de concentração, só começaria a ser tornada viável - como aponta inicialmente Hannah Arendt em The rights of men. What are they? (1949) e desenvolve depois em The origins of totalitarianism - se o direito a ter direitos tivesse uma tutela internacional, homologadora do ponto de vista da humanidade. Nas palavras de Hannah Arendt, no fecho deste artigo de 1949: "This human right, like all other rights can exist only through mutual agreement and guarantee. Transcending the rights of the citizen - being the right of men to citizenship - this right is the only one that can and can only be guaranted by the comunity of nations". Em síntese, para usar uma linguagem contemporânea, à medida em que o direito a ter direitos se convertesse numa tema global, de governança da ordem mundial, a transcender as soberanias, ex vi da inserção operativa de uma razão abrangente da humanidade. (LAFER, 1997)
\end{abstract}

Agamben, embora não ofereça uma solução a esse dilema, observa, como dito alhures, que nunca houve no âmbito do direito público o desenvolvimento de uma teoria geral do estado de exceção, de modo que pudessem ser examinados e propostos limites, condicionamentos, balizas ao exercício do poder soberano (AGAMBEN, 2004, P. 11). Obviamente, ainda que essa não seja a chave para o problema, poderia muito bem ser o pontapé inicial a uma relevante discussão sobre o assunto, compreendendo que essas violações de direitos humanos em 
períodos de instabilidade e insegurança não guardam pertinência apenas a uma questão política, mas também, e principalmente, a uma questão concernente à Ciência Jurídica.

Quiçá, a partir de um exame crítico sobre o poder soberano e da assunção pelo Direito de parcela de responsabilidade sobre a resolução dos conflitos decorrentes de seu exercício indiscriminado, será possível imaginar um processo de "descoisificação" do ser humano, de modo que a vida digna seja o valor a ser considerado em todos os propósitos adotados no plano das decisões políticas.

\section{CONCLUSÃO}

A cultura do egoísmo e da desvalorização da humanidade ainda assola o mundo, surpreendentemente após a Segunda Guerra Mundial, marco a partir do qual se desenvolveu com proficuidade o tema relativo aos Direitos Fundamentais e, consequentemente, dos Direitos Humanos, com a compreensão de sua indispensável codificação, acompanhada da criação de organismos internacionais e mecanismos convencionais e extraconvencionais dispostos a sua tutela internacional. Vê-se, não raramente, que a despeito de todas essas medidas, o ser humano, assim como ocorreu naqueles sistemas totalitários, ainda é encarado como objeto, por vezes sem qualquer valor, com a possibilidade de tornar-se, permanentemente, um "homo sacer", sempre que sua existência se afigurar incômoda ao exercício do poder soberano ou configurarse em um perigo real, potencial ou virtual à dita segurança do Estado.

Pautadas no exercício de um poder soberano ilimitado, as nações criam verdadeiros estados de exceção, “essa terra de ninguém” (AGAMBEN, 2004, p. 12) em que tudo é (ou volta a ser) possível, não havendo distinção entre democracia e totalitarismo, e onde o estado de natureza (antes justificativa à teoria contratual do Estado soberano) adentra o território do Estado, criando novos "homo sacers", cuja noção de inclusão a uma classe (nacional ou cidadão) e/ou de pertencimento à espécie humana se perdem. A exceção soberana, portanto, é essa figura limite em que há "a crise radical de toda possibilidade de distinguir com clareza entre pertencimento e inclusão, entre o que está fora e o que está dentro, entre exceção e norma" (AGAMBEM, 2007, p. 32)

O poder constituído, que depende da existência prévia do Estado e que possui a função de manter o direito criado e imposto pelo poder constituinte, passa a exercer um papel de protetor da soberania nacional, e, logo, ser um colaborador para imposição desse mesmo poder soberano (ainda que violento e tirânico). 
E nesse cenário, torna-se comum presenciarmos episódios de evidentes barbáries, que são veiculados pelos mais diversos meios de comunicação, capazes de difundir o terror por todo o planeta. São extremistas religiosos que exterminam iguais por divergências de crenças, são refugiados da guerra que morrem em busca de um lugar nos quais possam viver dignamente, são países que passam a adotar medidas radicais e contrárias, até mesmo, às convenções internacionais das quais são signatários para, supostamente, proteger o "seu povo", segregando outra parcela da população, que passa a ser considerada indesejada.

E no caso utilizado como exemplo no decorrer do presente artigo não foi diferente, pois após o atentado ocorrido em novembro de 2015 em Paris, o presidente francês François Hollande propôs a modificação da Constituição Francesa, para que aqueles que venham a ser tidos por "terroristas" percam a nacionalidade, o que viola diretamente o artigo $3^{\circ}$ da Convenção Europeia dos Direitos do Homem, da qual o país é signatário, e que prevê que ninguém pode ser expulso, nem privado de entrar no território do Estado de que for cidadão.

Nesse quadrante, torna-se nítido o surgimento de um estado de exceção na França, de consequências ainda incalculáveis, mas já habilitado a promover a marginalização de uma parcela considerável da população que, pela exceção, fora abandonada pelo Ordenamento Jurídico - com detenções de "suspeitos" de terrorismo e revisão de domicílios dia ou noite sem prévia determinação judicial, entre outras medidas questionáveis. É dizer: o exercício indiscriminado do poder soberano enseja (e ensejará) no surgimento de um grupo de pessoas desprovidas de quaisquer direitos, verdadeiros párias no mundo.

E diante de todo o exposto no presente estudo, chega-se à conclusão que o exercício indiscriminado da soberania e, de forma reflexa, do poder constituído é capaz de impossibilitar o efetivo exercício dos Direitos Humanos no âmbito internacional, chegando, muitas vezes, até a violá-lo, como no exemplo da França.

Assim entende-se que a relativização do exercício dos referidos poderes (soberano e constituído), aliado ao bom senso dos seus detentores, pode ser um excelente caminho para a aplicabilidade universal dos direitos que possuem como fim proteger a espécie humana. 


\section{REFERÊNCIAS}

AGAMBEN, G. Homo Sacer: o poder soberano e a vida nua I. Belo Horizonte: Ed. UFMG, 2004.

Estado de Exceção. São Paulo: Boitempo, 2004 (Estado de Sítio).

ARENDT, Hannah. A Condição Humana. $10^{\circ}$ ed. Rio de Janeiro: Ed. Forense Universitária, 2000.

CAÑAS, Gabriela; YÁRNOZ, Carlos. França mudará sua Constituição para combater o jihadismo. El País. Paris: 16 nov. 2015. Disponível em: http://brasil.elpais.com/brasil/2015/11/16/internacional/1447691479_418681.html. Acesso em: 16 de novembro de 2015.

FERREIRA, Helder. Judith Butler reflete sobre atentados em Paris. Revista Cult. São Paulo: publicação exclusiva do site, novembro, 2015. Disponível em: http://revistacult.uol.com.br/home/2015/11/judith-butler-reflete-sobre-atentados-em-paris/.

Acesso em: 22 de dezembro de 2015.

FUKS, Betty. Trauma e Cultura do Extermínio. Revista Cult. São Paulo: n. 205, ano 18, set. 2015. Disponível em: http://revistacult.uol.com.br/home/2015/08/betty-fuks/. Acesso em: 22 de dezembro de 2015.

LAFER, Celso. A reconstrução dos direitos humanos: a contribuição de Hannah Arendt. Estud. av., v.11, n.30, São Paulo, maio/ago. 1997. Disponível em: http://dx.doi.org/10.1590/S0103-40141997000200005. Acesso em: 30 de dezembro de 2015.

SANFE, Carla Orlandina. Paris - caindo na própria armadilha. Jornal Correio do Brasil. São Paulo: 29 nov. 2015. Disponível em: http://www.correiodobrasil.com.br/caindo-napropria-armadilha. Acesso em: 22 de dezembro de 2015. 